\title{
Kunnskapsbasert folkehelse - eksempel fysisk aktivitet
}

\author{
Eva Denison
}

Seksjon for forebyggende, helsefremmende og organisatoriske tiltak, Nasjonalt kunnskapssenter for helsetjenesten

E-post: eva.denison@kunnskapssenteret.no Telefon: 46400496

\section{SAMMENDRAG}

Kunnskapsbasert folkehelse er et relativt nytt begrep hvor a) behov og verdier i populasjonen, b) sosiale og lokale forhold, c) tilgjengelige ressurser, og d) beste tilgjengelige kunnskap fra forskning inkluderes $i$ beslutningsgrunnlaget for valg av tiltak for å bedre folkehelsen. I artikkelen brukes fysisk aktivitet som eksempel for å illustrere hva kunnskapsbasert folkehelse kan innebære i praksis. Flere store undersøkelser basert på representative utvalg viser at det fysiske aktivitetsnivået i den norske befolkningen er lavt. Vi vet fra internasjonale studier at store forandringer av fysiske omgivelser, arbeidsliv og bruk av transportmidler har redusert fysisk aktivitet betraktelig over de siste tiårene. Det fysiske aktivitetsnivået er dessuten skjevt fordelt i befolkningen. Personer med høy utdanning har for eksempel høyere aktivitetsnivå enn personer med lav utdanning. I Norge kanaliseres offentlige midler for å fremme fysisk aktivitet til organisert idrett, satsing på egenorganisert idrett og friluftsliv, og målrettede satsinger på å nå de fysisk inaktive. Systematisk oppsummert kunnskap om effekt av tiltak for økt fysisk aktivitet viser at tiltak på individnivå gir en liten til moderat økning av fysisk aktivitet på kort sikt, at tiltak i skolen øker varighet av fysisk aktivitet $\mathrm{i}$ skolen for barn og ungdom, og at enkle, konkrete tiltak på samfunnsnivå øker fysisk aktivitet noe.

\section{Denison E. Evidence-based public health: The example of physical activity. Nor J Epidemiol 2013; 23 (2): 181-185.}

\section{ENGLISH SUMMARY}

Evidence-based public health is a relatively new concept implying that decisions about interventions in the public health area be based on a) population needs and values, b) social and local contexts, c) available resources, and d) the best available scientific evidence. In this article physical activity is used to illustrate evidence-based public health in practice. Several large studies based on representative samples have demonstrated that the level of physical activity in the Norwegian population is low. International studies have shown that big changes in our physical environments, working lives, and transportation over the latest decades have reduced the level of physical activity substantially. In addition, the level of physical activity is skewed in the population. Persons with higher education are for example more active than persons with lower education. Public resources for physical activity in Norway are directed to organized sports, to initiatives for self-organized physical activity in sports and outdoor life, and to efforts to reach the physically inactive. Systematic reviews about effects of interventions to increase physical activity show that interventions targeting individuals give small to moderate increases of physical activity in the short term, that school based interventions increase the duration of physical activity in children and adolescents, and that simple, concrete interventions at the community level increase physical activity somewhat.

This is an open access article distributed under the Creative Commons Attribution Licence, which permits unrestricted use, distribution, and reproduction in any medium, provided the original work is properly cited.

\section{INNLEDNING}

I denne artikkelen vil jeg bruke fysisk aktivitet som et gjennomgående tema for å illustrere kunnskapsbasert folkehelse.

Med fysisk aktivitet mener vi all bevegelse som produseres av skjelettmuskulatur som resulterer i energiforbruk. Det fysiske aktivitetsnivået kan defineres basert på hyppighet, varighet, intensitet og type av aktivitet (1). Fysisk aktivitet skjer på alle områder i livet. En vanlig inndeling av aktiviteter er i a) fritid, b) arbeidsliv eller skole, c) transport og d) husholdning (2).

Fysisk inaktivitet, det vil si at det fysiske aktivitetsnivået er under et minimum, er nå den fjerde største risikofaktoren for dødelighet globalt sett. Det er estimert at $21-25 \%$ av sykdomsbyrden som skyldes bryst- og tykktarmskreft, $27 \%$ av diabetes, og $30 \%$ av iskemisk hjerte- og karsykdom kan tilskrives fysisk inaktivitet $(3,4)$. Det ser derfor ut til at det er store gevinster for folkehelsen ved å øke nivået av fysisk aktivitet i befolkningen (5).

\section{KUNNSKAPSBASERT FOLKEHELSE}

Med kunnskapsbasert folkehelse menes at følgende elementer brukes som grunnlag for beslutninger om helsefremmende eller forebyggende tiltak (6):

- behov, verdier og preferanser i populasjonen

- omgivelser, sosiale forhold og organisatorisk kontekst

- tilgjengelige ressurser

- beste tilgjengelige kunnskap fra forskning 
I det følgende gis eksempler på momenter som kan være aktuelle å ta inn i et beslutningsgrunnlag for valg av tiltak for å fremme fysisk aktivitet, som en illustrasjon på hva "kunnskapsbasert folkehelse" kan innebære i praksis.

\section{Behov, verdier og preferanser i populasjonen}

Hvor mye fysisk aktivitet trengs for å gi helsegevinst? Verdens helseorganisasjon har laget anbefalinger om dette basert på systematiske kunnskapsoppsummeringer (5). Det anbefales at barn og ungdommer (5-17 år) har et aktivitetsnivå på minimum 60 minutter moderat intensitet per dag. Det meste av dette skal være aerobisk aktivitet. Tre ganger per uke bør aktiviteten være intens og inkludere styrketrening. For voksne (over 18 år) er minimumsnivået 150 minutter moderat intensitet per uke eller 75 minutter intens fysisk aktivitet per uke, eller en likeverdig kombinasjon. Det meste skal være aerobisk aktivitet. Intens aktivitet, inkludert styrketrening bør utføres to ganger per uke. For eldre anbefales dessuten aktiviteter som fremmer balanse og motvirker fall, tre ganger per uke.

Det faktiske nivået av fysisk aktivitet $\mathrm{i}$ befolkningen samsvarer ikke med disse anbefalingene. Tilgjengelige data fra 122 land (7) viser at cirka $31 \%$ av verdens voksne befolkning er mindre fysisk aktive enn anbefalt minimumsnivå. Det er imidlertid store regionale variasjoner - i Europa er $35 \%$ av den voksne befolkningen aktive under minimumsnivået, mens i Nord- og SørAmerika er tilsvarende andel $42 \%$. Data fra 105 land viser at rundt $80 \%$ av 13-15-åringer ikke er fysisk aktive 60 minutter per dag. I Norge viser resultatene fra en nasjonal undersøkelse at $80 \%$ av den voksne befolkningen ikke er fysisk aktiv på minimumsnivået ( $78 \%$ av mennene og $82 \%$ av kvinnene). Dette skyldes først og fremst at hverdagsaktivitetene har gått ned (8). Blant 6-åringene i Norge tilfredsstiller $87 \%$ av jentene og $96 \%$ av guttene anbefalingene for fysisk aktivitet. Blant 9-åringene tilfredsstiller $70 \%$ av jentene og $86 \%$ av guttene anbefalingene, mens tilsvarende tall blant 15-årige jenter og gutter er $43 \%$ og $58 \%$ (9).

Disse tallene kan imidlertid ikke uten videre sammenlignes - de internasjonale tallene (7) er basert på selvrapportering ved spørreskjema mens tallene for norske voksne er basert på måling med akselerometer (8). Tallene for norske barn er basert på selvrapportering og måling med akselerometer (9). Spørreskjemaer for selvrapportering av fysisk aktivitet har generelt lav reliabilitet og validitet (10). Akselerometer er en objektiv målemetode som fanger det meste, men ikke alt av daglige aktiviteter slik at underestimering er mer sannsynlig enn overestimering (11).

Alder, kjønn, helsetilstand, mestringsfølelse og tidligere nivåer av fysisk aktivitet er konsistente korrelater til fysisk aktivitet $\mathrm{i}$ internasjonal litteratur (12). Vi vet en del om hvilke fysiske aktiviteter nordmenn driver med $i$ fritiden fra en undersøkelse gjennomført av Breivik og Rafoss på oppdrag fra Nasjonalt råd for fysisk aktivitet (13). Undersøkelsen er basert på et representativt utvalg av nordmenn (15 år og eldre) som ble gjennomført i 2011. Såkalte "store" folkeaktiviteter som involverer mer enn $20 \%$ av befolkningen er fotturer i skog og mark, skiturer i skog og fjell, styrketrening, fotturer på fjell og vidde, jogging, sykling til jobb, langrenn og sykling som trening. Overlegent størst oppslutning har fotturer i skog og mark hvor $66 \%$ sier at de gjør dette "minst en gang i måneden i sesongen". De aller fleste bedriver fysisk aktivitet på egen hånd eller sammen med familie og venner. Undersøkelsen til Breivik og Rafoss (13) viser også at de aller fleste voksne trener for å få mentalt og fysisk overskudd, og for å forebygge helseplager, mens for ungdommer er viktige motiv å konkurrere og få utfordringer. Mangel på tid var den eneste barrieren som opplevdes å ha stor betydning for mer enn $20 \%$ av befolkningen.

\section{Omgivelser, sosiale forhold og organisatorisk kontekst}

Økologiske modeller har til hensikt å beskrive komplekse sammenhenger mellom flere nivåer i samfunnet og brukes innen mange forskjellige forskningsområder. For forskning på fysisk aktivitet er sosiale forhold, fysiske omgivelser, og lovgivning og regulering eksempler på kategorier som brukes i slike modeller (2). Store forandringer av fysiske omgivelser, arbeidsliv og bruk av transportmidler har redusert fysisk aktivitet betraktelig. For eksempel rapporteres det om en $30 \%$ reduksjon av transport til fots i USA fra 1977 til 1995 (2). Parker og andre grøntområder kan ha stor betydning for fysisk aktivitet, spesielt i urbane strøk. Sikkerhet, estetikk, fasiliteter, vedlikehold og nærhet er vist å være av betydning med tanke på om parker oppfattes som egnet til fysisk aktivitet (14).

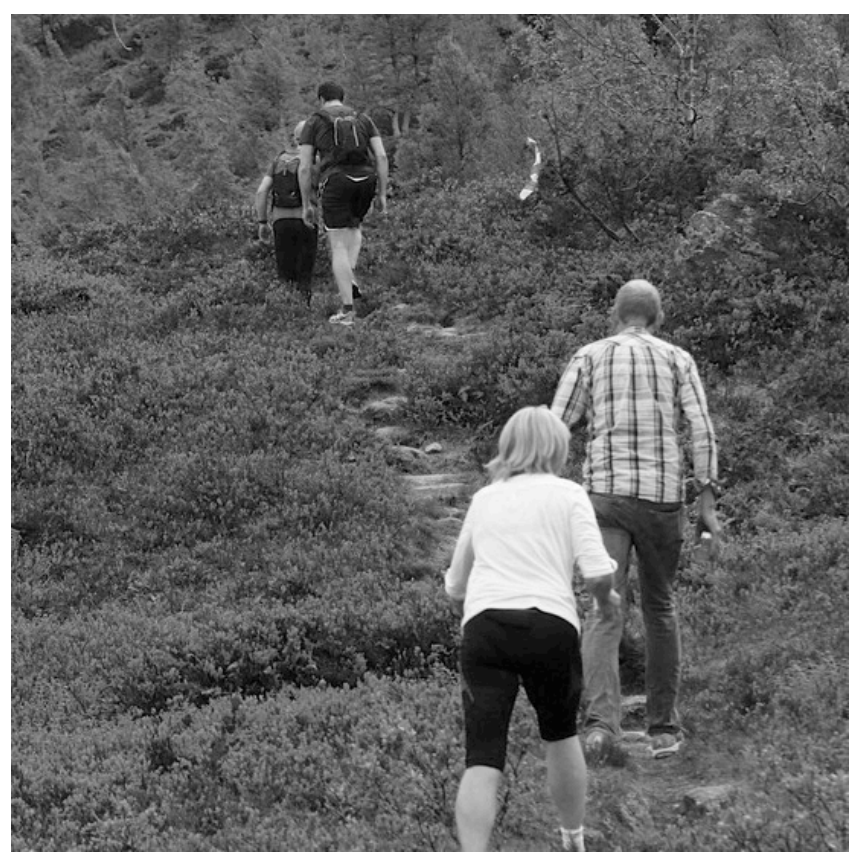

Figur 1. Fotturer i skog og mark er en av de mest utbredte formene for fysisk aktivitet blant nordmenn (foto: Helge Fuglseth, kondis.no). 
Andre modeller fokuserer på sosiale determinanter for folkehelse som sosioøkonomiske forhold og posisjon i samfunnet, eksponering på populasjonsnivå, sårbarhet på populasjonsgruppenivå, og helseutfall og konsekvenser på individnivå (5). Til støtte for disse modellene er det vist at økonomiske forhold, samfunnsnormer, urbanisering og industrialisering er konsistente korrelater til fysisk aktivitet i internasjonal litteratur (12). Norske tall viser at utdanningsnivå, hjemmeforhold og nærmiljø har sammenheng med fysisk aktivitetsnivå. Personer med høyere utdanning har høyere aktivitetsnivå. Det samme gjelder for personer som opplever at fysisk aktivitet blir snakket om på en positiv måte hjemme eller som opplever at det er mange steder å være fysisk aktiv, at det er tilrettelagt for fysisk aktivitet, og at det er kort vei til butikker (8). Denne type assosiasjoner kan riktignok ikke uten videre tolkes som årsakssammenhenger.

\section{Tilgjengelige ressurser}

Folkehelsearbeid utøves både gjennom helsefremmende og forebyggende innsatser og kan være rettet mot befolkningen, undergrupper av befolkningen, eller mot enkeltindivider (15). Hvordan ressurser fordeles på disse områdene er avhengig av mange faktorer, men det vil være behov for innsatser på alle nivåer $(15,16)$.

Offentlige tilskudd til fysisk aktivitet i Norge kanaliseres i stor grad som spillemidler til idretten via Kulturdepartementet og skjer i samspill med kommunale anleggsmidler (17). I Stortingsmeldingen "Den norske idrettsmodellen" omtales, utover satsing på idrett i bred forstand, satsing på egenorganisert idrett og friluftsliv, og målrettede satsinger for å nå de fysisk inaktive (17).

Den nye folkehelseloven pålegger kommuner og fylkeskommuner et betydelig ansvar for å gjennomføre tiltak for fysisk aktivitet i alle lag av befolkningen (18). Eksempler på slike bidrag er å sikre grøntarealer, nærmiljøanlegg, lysløyper, turstier, og gang- og sykkelveier (13).

Når det gjelder forebyggende helsetjenester foregår det en større satsing på kommunale frisklivssentraler for veiledning og oppfølging innenfor områdene fysisk aktivitet, kosthold og tobakk. Frisklivssentralen har et strukturert henvisnings- og oppfølgingssystem for personer som har behov for endring av atferd, for eksempel å øke sitt fysiske aktivitetsnivå. Personer kan henvises av fastlege, helsepersonell i primær- og spesialisthelsetjenesten, eller NAV, eller de kan henvende seg direkte til frisklivssentralen selv (19).

\section{Den beste tilgjengelige kunnskapen fra forskning}

Kunnskap på folkehelseområdet gjelder oftest kunnskap om helsetilstanden i en befolkning, kunnskap om årsaker til sykdom, og kunnskap om effekter av tiltak for å bedre helsetilstanden (15). I avsnittene ovenfor er det referert til både internasjonal og nasjonal litteratur for å beskrive nivåer av og variasjon i fysisk aktivitet og mulige årsaker til det generelt lave nivået. Det vil også være behov for kunnskap om lokale forhold, for eksempel når kommuner og fylkeskommuner skal planlegge tiltak for økt fysisk aktivitet blant sine innbyggere. For eksempel kan resultater fra nasjonale undersøkelser gjøres tilgjengelige på kommunenivå (15).

Når det gjelder effekter av tiltak for å øke fysisk aktivitet finnes det forholdsvis mye primærforskning, og det kommer stadig flere systematiske oversikter som oppsummerer det som forefinnes av effektstudier på dette området. Kunnskap som er oppsummert på en systematisk måte besvarer et spesifikt spørsmål, har klare inklusjons- og eksklusjonskriterier, er basert på alle tilgjengelige relevante studier, og kvaliteten på dokumentasjonen er vurdert (20). Tabell 1 sammenfatter noe av den systematisk oppsummerte kunnskapen om effekt av tiltak for bedre folkehelse som er blitt publisert de seneste årene. Generelt kan vi si at tiltak på individnivå gir en liten til moderat økning av fysisk aktivitet på kort sikt (21-25), at tiltak i skolen øker varighet av fysisk aktivitet per uke for barn og ungdom, og hyppighet for barn (26), og at enkle (22), tiltak på samfunnsnivå øker fysisk aktivitet noe. Sammensatte tiltak ser derimot ut til å ha liten eller ingen effekt (27). Alle oversiktene som er referert i tabell 1 konkluderer med at kvaliteten på dokumentasjonen stort sett er lav, og at de rapporterte effektestimatene er usikre. Dette bør ikke tolkes som at tiltak for å øke fysisk aktivitet ikke virker - at dokumentert effekt mangler er ikke det samme som at manglende effekt er dokumentert.

Det er mange utfordringer med å oppsummere forskning om effekter av tiltak for økt fysisk aktivitet. Populasjonene, tiltakene og utfallene kan variere så mye på tvers av studiene at det er vanskelig å oppsummere resultatene på en fornuftig måte. Det samme gjelder for resultatene i seg selv - hva er "den sanne effekten" når resultatene i spriker mye fra én studie til en annen, og en tredje? Metoder for måling av fysisk aktivitet er en annen utfordring. Å bruke spørreskjemaer er praktisk og billig og det finnes over 80 (versjoner av) spørreskjemaer for å måle fysisk aktivitet. Det er imidlertid dokumentert at få av disse har høy reliabilitet og validitet, og nesten ingen er testet med hensikt på responsivitet, det vil si evnen til å fange endringer over tid (10). Andre, mer objektive måter å måle fysisk aktivitet på er ofte dyre, gir ikke informasjon om alle aspekter ved fysisk aktivitet, eller de gir data som krever avanserte analyser (11).

\section{KUNNSKAPSBASERT FOLKEHELSE I PRAKSIS}

Vi har sett i dette eksemplet at kunnskap om befolkningens fysiske aktivitetsnivå, faktorer som er av betydning for fysisk aktivitet og inaktivitet, og effekter av tiltak kommer fra flere forskjellige kilder på lokalt, nasjonalt og internasjonalt nivå. Kunnskapssenterets oppgave er å oppsummere forskning om effekter av tiltak for økt fysisk aktivitet på bestilling fra Helsedirektoratet eller andre aktører i feltet, for eksempel kommuner og fylkeskommuner.

Ett aktuelt eksempel er Helsedirektoratets arbeid 
Tabell 1. Resultater fra aktuelle systematiske oversikter over effekter av tiltak for økt fysisk aktivitet.

\begin{tabular}{|c|c|c|c|c|c|c|c|}
\hline Forfatter & Nivå & Studiedesign & Populasjon & Tiltak & Sammenligning & Utfall & Resultat \\
\hline $\begin{array}{l}\text { Baker } \\
2011(27)\end{array}$ & Samfunn & $\begin{array}{l}\text { Randomiserte } \\
\text { og ikke- } \\
\text { randomiserte } \\
\text { kontrollerte } \\
\text { studier }\end{array}$ & $\begin{array}{l}\text { Personer i } \\
\text { geografisk } \\
\text { definerte områder }\end{array}$ & $\begin{array}{l}\text { Kombinasjoner av to eller flere } \\
\text { tiltak: sosial markedsføring, } \\
\text { andre kommunikasjonsstrate- } \\
\text { gier; rådgivning fra helseperso- } \\
\text { nell, samarbeid med statlige } \\
\text { eller frivillige organisasjoner; } \\
\text { tiltak i spesifikke settinger; } \\
\text { endring av miljøer }\end{array}$ & $\begin{array}{l}\text { Personer i andre } \\
\text { geografisk } \\
\text { definerte } \\
\text { områder }\end{array}$ & $\begin{array}{l}\text { Grad av fysisk ak- } \\
\text { tivitet i populasjo- } \\
\text { nen; prosentandel } \\
\text { aktive eller inakti- } \\
\text { ve; hyppighet; } \\
\text { prosentandel som } \\
\text { var aktive på } \\
\text { anbefalt nivå }\end{array}$ & $\begin{array}{l}26 \text { kontrollerte før- og etter- } \\
\text { studier ble inkludert. Ikke } \\
\text { evidens for at tiltak med flere } \\
\text { elementer rettet mot samfunn } \\
\text { eller lokalsamfunn øker fysisk } \\
\text { aktivitet }\end{array}$ \\
\hline $\begin{array}{l}\text { Davies } \\
2012(21)\end{array}$ & $\begin{array}{l}\text { Individ, } \\
\text { internett }\end{array}$ & $\begin{array}{l}\text { Randomiserte } \\
\text { og ikke- } \\
\text { randomiserte } \\
\text { kontrollerte } \\
\text { studier }\end{array}$ & $\begin{array}{l}\text { Voksne personer } \\
\geq 18 \text { år }\end{array}$ & $\begin{array}{l}\text { Individrettede tiltak for å } \\
\text { fremme fysisk aktivitet via } \\
\text { internett }\end{array}$ & $\begin{array}{l}\text { Personer som } \\
\text { ikke mottok } \\
\text { materialer via } \\
\text { internett }\end{array}$ & $\begin{array}{l}\text { Grad av fysisk } \\
\text { aktivitet }\end{array}$ & $\begin{array}{l}34 \text { studier ble inkludert. } \\
\text { Noe økt fysisk aktivitet på kort } \\
\text { sikt ble rapportert }\end{array}$ \\
\hline $\begin{array}{l}\text { Denison } \\
2010(22)\end{array}$ & $\begin{array}{l}\text { Individ, } \\
\text { utenfor } \\
\text { helsetje- } \\
\text { nesten }\end{array}$ & $\begin{array}{l}\text { Systematiske } \\
\text { oversikter av } \\
\text { høy kvalitet }\end{array}$ & $\begin{array}{l}\text { Voksne i og uten- } \\
\text { for arbeidslivet, } \\
\text { eldre, personer } \\
\text { med innvandrer- } \\
\text { bakgrunn (ikke } \\
\text { vestlige), personer } \\
\text { med funksjons- } \\
\text { nedsettelser som } \\
\text { lever i OECD-land }\end{array}$ & $\begin{array}{l}\text { Individrettede tiltak for å } \\
\text { fremme fysisk aktivitet i og } \\
\text { utenfor arbeidslivet }\end{array}$ & $\begin{array}{l}\text { Ingen tiltak eller } \\
\text { annet tiltak }\end{array}$ & $\begin{array}{l}\text { Grad av fysisk } \\
\text { aktivitet målt på } \\
\text { individnivå som } \\
\text { atferd eller ved } \\
\text { energiforbruk }\end{array}$ & $\begin{array}{l}6 \text { systematiske oversikter ble } \\
\text { inkludert. Sosial støtte og } \\
\text { støtte via internett eller telefon } \\
\text { gav økning av fysisk } \\
\text { aktivitetsnivå på kort sikt }\end{array}$ \\
\hline $\begin{array}{l}\text { Orrow } \\
2012(23)\end{array}$ & $\begin{array}{l}\text { Individ, } \\
\text { primær- } \\
\text { helse- } \\
\text { tjeneste }\end{array}$ & $\begin{array}{l}\text { Randomiserte } \\
\text { kontrollerte } \\
\text { studier }\end{array}$ & $\begin{array}{l}\text { Voksne } \geq 16 \text { år } \\
\text { fysisk inaktive, } \\
\text { rekruttering i } \\
\text { primærhelse- } \\
\text { tjeneste }\end{array}$ & $\begin{array}{l}\text { Tiltak for å fremme fysisk } \\
\text { aktivitet }\end{array}$ & $\begin{array}{l}\text { Ingen tiltak eller } \\
\text { annet tiltak }\end{array}$ & $\begin{array}{l}\text { Grad av fysisk } \\
\text { aktivitet eller } \\
\text { kondisjon }\end{array}$ & $\begin{array}{l}15 \text { studier ble inkludert. } \\
\text { Liten til moderat økning av } \\
\text { fysisk aktivitet } 12 \text { måneder } \\
\text { etter randomisering }\end{array}$ \\
\hline $\begin{array}{l}\text { Denison } \\
2012(24)\end{array}$ & $\begin{array}{l}\text { Individ, } \\
\text { primær- } \\
\text { helse- } \\
\text { tjeneste }\end{array}$ & $\begin{array}{l}\text { Randomiserte } \\
\text { og ikke- } \\
\text { randomiserte } \\
\text { kontrollerte } \\
\text { studier }\end{array}$ & $\begin{array}{l}\text { Voksne personer } \\
\geq 18 \text { år, fysisk } \\
\text { inaktive }\end{array}$ & $\begin{array}{l}\text { Individuell veiledning, } \\
\text { organisert gruppetrening, } \\
\text { trening med lag/foreninger } \\
\text { eller private aktører, trenings- } \\
\text { kontakt med organisert } \\
\text { oppfølging tilsvarende tiltak i } \\
\text { frisklivssentraler }\end{array}$ & $\begin{array}{l}\text { Rådgiving (sam- } \\
\text { tale med eller } \\
\text { uten skriftlig } \\
\text { informasjon), } \\
\text { ingen tiltak, } \\
\text { eller annen } \\
\text { vanlig praksis }\end{array}$ & $\begin{array}{l}\text { Grad av fysisk } \\
\text { aktivitet }\end{array}$ & $\begin{array}{l}14 \text { randomiserte kontrollerte } \\
\text { studier ble inkludert. } \\
\text { Henvisning til lokale } \\
\text { treningstilbud med oppfølging } \\
\text { og egenadministrert trening } \\
\text { med oppfølging gav økt fysisk } \\
\text { aktivitet på kort sikt }\end{array}$ \\
\hline $\begin{array}{l}\text { Pavey } \\
2011(25)\end{array}$ & $\begin{array}{l}\text { Individ, } \\
\text { primær- } \\
\text { helse- } \\
\text { tjeneste }\end{array}$ & $\begin{array}{l}\text { Randomiserte } \\
\text { og ikke- } \\
\text { randomiserte } \\
\text { kontrollerte } \\
\text { studier }\end{array}$ & $\begin{array}{l}\text { Fysisk inaktive } \\
\text { personer med eller } \\
\text { uten medisinske } \\
\text { diagnoser, rekrut- } \\
\text { tering i primær- } \\
\text { helsetjeneste }\end{array}$ & $\begin{array}{l}\text { Henvisning til fysisk aktivitet } \\
\text { eller trening med oppfølging }\end{array}$ & $\begin{array}{l}\text { Rådgiving (sam- } \\
\text { tale med eller } \\
\text { uten skriftlig } \\
\text { informasjon), } \\
\text { ingen tiltak, el- } \\
\text { ler andre former } \\
\text { av henvisning }\end{array}$ & $\begin{array}{l}\text { Grad av fysisk } \\
\text { aktivitet }\end{array}$ & $\begin{array}{l}8 \text { randomiserte studier ble } \\
\text { inkludert. Noe økt fysisk } \\
\text { aktivitet på kort sikt } \\
\text { sammenlignet med ingen } \\
\text { tiltak, ellers usikre resultat }\end{array}$ \\
\hline
\end{tabular}

med å revidere Veileder for kommunale frisklivssentraler (19). Direktoratet bestilte en oppsummering av forskning om effekter av tiltak som går over tre måneder og tilbys frisklivssentraler. Rapporten (24) ble brukt som en del av grunnlaget for veilederen. Da det er vanlig praksis at tiltakene tilbys over flere reseptperioder, har Kunnskapssenteret også fått i oppdrag å oppsummere forskning om effekter av tiltak som varer i mer enn tre måneder (ferdigstilles i første kvartal 2014). 


\section{REFERANSER}

1. Caspersen C, Powell K, Christenson G. Physical activity, exercise and physical fitness: definitions and distinctions for health-related research. Public Health Rep 1985; 100: 126-135.

2. Sallis J, Floyd M, Rodríguez D, Saelens B. Role of built environments in physical activity, obesity, and cardiovascular disease. Circulation 2012; 125: 729-737.

3. Global status report on noncommunicable diseases 2010. Geneva: World Health Organization, 2011.

4. 2008 Physical Activity Guidelines for Americans. Washington D.C.: U.S. Department of Health and Human Services, 2008.

5. Global Recommendations on Physical Activity for Health. Geneva: World Health Organization, 2010.

6. Brownson R, Baker E, Leet T, Gillespie K, True W. Evidence-based public health, $2^{\text {nd }}$ edn. Oxford: Oxford University Press, 2011.

7. Hallal P, Andersen L, Bull F, Guthold R, Haskell W, Ekelund U. Global physical activity levels: surveillance progress, pitfalls, and prospects. Lancet 2012; 380: 247-57.

8. Fysisk aktivitet blant voksne og eldre i Norge. Resultater fra en kartlegging $i 2008$ og 2009. Oslo: Helsedirektoratet, 2009.

9. Fysisk aktivitet blant 6-, 9- og 15-åringer $i$ Norge. Resultater fra en kartlegging i 2011. Oslo: Helsedirektoratet, 2012.

10. van Poppel M, Chinapaw M, Mokkink L, van Mechelen W, Terwee C. Physical activity questionnaires for adults: a systematic review of measurement properties. Sports Med 2010; 40: 565-600.

11. Warren J, Ekelund U, Bessond H, Mezzani A, Geladas N, Vanheesh L. Assessment of physical activity - a review of methodologies with reference to epidemiological research: a report of the exercise physiology section of the European Association of Cardiovascular Prevention and Rehabilitation. Eur J Cardiovasc Prev Rehabil 2010, 17: 127-139.

12. Bauman A, Reis R, Sallis J, Wells J, Loos R, Martin B. Correlates of physical activity: why are some people physically active and others not? Lancet 2012; 380: 258-271.

13. Breivik G, Kolfoss G. Fysisk aktivitet; omfang, tilrettelegging og sosial ulikhet - en oppdatering og revisjon. Norges Idrettshøgskole og Høgskolen i Finnmark, 2012.

14. McCormack G, Rock M, Toohey A, Hignell D. Characteristics of urban parks associated with park use and physical activity: A review of qualitative research. Health Place 2010; 16: 712-726.

15. Folkehelsearbeidet - veien til god helse for alle. Oslo: Helsedirektoratet, 2010.

16. Rose G. Sick individuals and sick populations. Int $j$ Epidemiol 1985; 14: 32-38.

17. Meld. St. 26 (2011-2012). Melding til Stortinget. Den norske idrettsmodellen. Oslo: Kulturdepartementet, 2012.

18. Lov om folkehelsearbeid. Oslo: Helse-og omsorgsdepartementet, 2011.

19. Veileder for kommunale frisklivssentraler - Etablering og organisering, revidert utgave. Oslo: Helsedirektoratet, 2013. Tilgjengelig fra www.helsedirektoratet.no.

20. Jamtvedt G. Systematiske oversikter om effekt av tiltak. Norsk Epidemiologi 2013; 23 (2): 119-124.

21. Davies C, Spence J, Vandelanotte C, Caperchione C, Mummery K. Meta-analysis of internet-delivered interventions to increase physical activity levels. Int J Behav Nutr Phys Act 2012; 9: 52.

22. Denison E, Underland V, Nilsen ES, Fretheim A. Effekter av tiltak utenfor helsetjenesten for å øke fysisk aktivitet hos voksne. Rapport fra Kunnskapssenteret nr 19-2010. Oslo: Nasjonalt kunnskapssenter for helsetjenesten, 2010.

23. Orrow G, Kinmonth A, Sanderson S, Sutton S. Effectiveness of physical activity promotion based in primary care: systematic review and meta-analysis of randomised controlled trials. BMJ 2012; 344: e1389.

24. Denison E, Vist GE, Underland V, Berg RC. Effects of organized follow-up of behaviour that may increase risk of disease in adults. Report from Kunnskapssenteret no. 12-2012. Oslo: Norwegian Knowledge Centre for the Health Services, 2012.

25. Pavey T, Taylor A, Fox K, Hillsdon M, Anokye N, Campbell J, et al. Effect of exercise referral schemes in primary care on physical activity and improving health outcomes: systematic review and meta-analysis. $B M J$ 2011; 343: d6462.

26. Dobbins M, Husson H, DeCorby K, LaRocca RL. School-based physical activity programs for promoting physical activity and fitness in children and adolescents aged 6 to 18. Cochrane Database of Systematic Reviews 2013, Issue 2. Art. No.: CD007651. DOI: 10.1002/14651858.CD007651.pub2.

27. Baker PRA, Francis DP, Soares J, Weightman AL, Foster C. Community wide interventions for increasing physical activity. Cochrane Database of Systematic Reviews 2011, Issue 4. Art. No.: CD008366. DOI: 10.1002/14651858.CD008366.pub2. 